\title{
Lymphoepithelioma-Like Hepatocellular Carcinoma
}

National Cancer Institute

\section{Source}

National Cancer Institute. Lymphoepithelioma-Like Hepatocellular Carcinoma. NCI

Thesaurus. Code C96788.

A rare type of hepatocellular carcinoma characterized by the presence of pleomorphic malignant cells that are intermixed with lymphocytes. 